\title{
COPD: the patient perspective
}

This article was published in the following Dove Press journal:

International Journal of COPD

19 February 2016

Number of times this article has been viewed

\author{
Paul W Jones' \\ Henrik Watz ${ }^{2}$ \\ Emiel FM Wouters ${ }^{3}$ \\ Mario Cazzola ${ }^{4}$ \\ 'Division of Clinical Science, \\ St George's, University of London, \\ London, UK; ${ }^{2}$ Pulmonary Research \\ Institute at Lung Clinic Grosshansdorf, \\ Airway Research Center North \\ (ARCN), Member of the German \\ Center for Lung Research (DZL), \\ Grosshansdorf, Germany; ${ }^{3} \mathrm{CIRO}+$, \\ Department of Respiratory Medicine, \\ Maastricht University, Maastricht, the \\ Netherlands; ${ }^{4}$ Unit of Respiratory \\ Clinical Pharmacology, Department \\ of Systemic Medicine, University of \\ Rome 'Tor Vergata,' Rome, Italy
}

Correspondence: Henrik Watz Pulmonary Research Institute at Lung Clinic Grosshansdorf, Airway Research Center North (ARCN), Member of the German Center for Lung Research (DZL), Woehrendamm 80, D-22927, Grosshansdorf, Germany

Tel $+494102888 I 122$

Fax +494I02 888I II4

Email h.watz@pulmoresearch.de
Abstract: Chronic obstructive pulmonary disease (COPD) is a highly prevalent disease characterized by nonreversible airway obstruction. Well-characterized symptoms such as exertional dyspnea and fatigue have a negative impact on patients' quality of life (QoL) and restrict physical activity in daily life. The impact of COPD symptoms on QoL is often underestimated; for example, $36 \%$ of patients who describe their symptoms as being mild-tomoderate also admit to being too breathless to leave the house. Additionally, early morning and nighttime symptoms are a particular problem. Methods are available to allow clinicians to accurately assess COPD symptoms, including patient questionnaires. Integrated approaches to COPD management, particularly pulmonary rehabilitation, are effective strategies for addressing symptoms, improving exercise capacity and, potentially, also increasing physical activity. Inhaled bronchodilators continue to be the mainstay of drug therapy in COPD, where options can be tailored to meet patients' needs with careful selection of the inhaled medication and the device used for its delivery. Overall, an integrated approach to disease management should be considered for improving QoL and subsequent patient outcomes in COPD.

Keywords: COPD, patients, physical activity levels, pulmonary rehabilitation

\section{Introduction}

Chronic obstructive pulmonary disease (COPD) is characterized by nonreversible airway obstruction. ${ }^{1}$ Highly prevalent worldwide, COPD significantly contributes to health care costs with high rates of morbidity and mortality. ${ }^{2,3} \mathrm{~A}$ diagnosis of COPD is determined by clinical assessment of airflow limitation and symptoms such as cough and wheeze; however, the detrimental effect of COPD symptoms on a patient's quality of life (QoL) is often underestimated. ${ }^{4}$

In order to better understand and address the impact of COPD symptoms from a patient's perspective, integrated approaches to disease assessment and management are required. ${ }^{5} \mathrm{~A}$ recent observational study found that, regardless of disease severity, more than half of patients experienced COPD symptoms throughout the whole 24-hour day, and nearly $80 \%$ of patients reported experiencing symptoms during at least two parts of the day. The presence of symptoms is associated with worse health status, depression, anxiety, and poor sleep quality. ${ }^{6}$ The management of patients with COPD and comorbidities remains particularly challenging. The presence of other chronic conditions increases symptom burden, reduces functional performance, has negative effects on health status, and management approaches need to be adapted accordingly.

The restriction of physical activity due to symptoms such as exertional dyspnea and fatigue also has a major adverse effect on a patient's QoL, ${ }^{7}$ while preserving or improving physical activity may have far-reaching benefits for hospitalization and mortality rates. ${ }^{8-10}$ The aims of this article are to evaluate the tools available for assessment of COPD symptoms and the impact of symptoms on the daily lives of patients. We will also outline current strategies for symptom improvement that could 
enhance patients' QoL and subsequent outcomes. This article was based on the proceedings of a session at the 1st World Lung Disease Summit held in Lisbon on November 15-17, 2013, which brought together experts in the field of COPD; this should therefore be considered as a review and discussion of recent advances in practice and clinical evidence rather than a systematic literature review.

\section{COPD symptoms}

\section{Common symptoms and impact on QoL}

The well-defined symptoms commonly reported by patients with COPD include cough, sputum production, wheeze, and breathlessness. ${ }^{11}$ However, the impact of symptoms on an individual patient's daily living activities varies depending on a number of factors, for example, their disease severity and comorbidities. ${ }^{12}$ The incidence and severity of symptoms also have a varying impact on a patient's QoL at different times of the day, with early morning and nighttime symptoms having a particularly detrimental influence on health status. ${ }^{13,14}$

Ensuring that all patients have the best possible QoL is a major goal in the treatment of COPD. QoL is an individual experience unique to each patient and cannot be measured in a standardized way; instead, health-status questionnaires are used to measure a patient's ability to engage in and enjoy normal activities. Multiple factors have an impact on measured health status, those with the largest impact being dyspnea, exercise tolerance, and psychological health. ${ }^{15}$ The impact of COPD symptoms on a patient's QoL is often underestimated; for instance, $36 \%$ of patients who describe their symptoms as being mild-to-moderate also admit to being too breathless to leave the house. ${ }^{4}$

\section{How to assess symptoms?}

A number of symptom questionnaires and disease-specific health-status measures are available to allow clinicians to accurately assess COPD symptoms to inform suitable treatment decisions. The Global initiative for chronic Obstructive Lung Disease (GOLD) 2006 staging system allowed for the determination of disease severity using forced expiratory volume in 1 second $\left(\mathrm{FEV}_{1}\right)$ as a measure of lung function, although the heterogeneity within COPD meant that this was not sufficient. This led to a new classification proposal in the GOLD 2011 strategy document, which included a measure of breathlessness (using the modified Medical Research Council [mMRC] dyspnea score) or a measure of health status (using the COPD Assessment Test [CAT] score). ${ }^{16}$

The mMRC dyspnea scale is an American Thoracic Society modification of the British MRC dyspnea index. ${ }^{16}$
Both scales are in wide use and it is important to be precise about which is being used, as the two have very similar wording for the categories (ranging from "only breathless during strenuous exercise" to "too breathless to leave the house, or when dressing or undressing"), but the mMRC grading ranges from 0 to 4 , whereas the British MRC scale ranges from 1 to $5 .{ }^{17}$

The CAT was developed as a reliable, brief, and simple test to accurately measure the key attributes of health in COPD patients. The CAT produces a reliable measure of COPD severity from the perspective of the patient with results that are relevant worldwide. ${ }^{18}$ A score of 10 on the CAT indicates the level at which the average COPD patient may benefit from long-acting bronchodilator treatment; however, this is only a guide as treatment decisions should be based on the individual needs of each patient. GOLD now recommends that, where possible, a comprehensive measure such as the CAT should be used to assess symptom level rather than the $\mathrm{mMRC}$, as the latter only addresses one impact of the disease.

In terms of health-status measurements, the St George's Respiratory Questionnaire (SGRQ), a standardized questionnaire comprising three sections (respiratory symptoms, impact of breathlessness, and impact on social functioning and psychological health), is widely used in clinical trials, but is too complex for routine use ${ }^{19}$ Conversely, the Clinical COPD Questionnaire (CCQ) was developed due to the need for a simple clinical tool to help evaluate the clinical status of the airways together with the patient's health status. As such, the CCQ includes items on the emotional function and limitations experienced by the patient. This questionnaire can assess the effectiveness of the clinical management of COPD and is a useful tool for clinicians. ${ }^{20}$

Each of these instruments has advantages and disadvantages (Table 1). For example, short questionnaires such as the CCQ and CAT are useful due to ease-of-completion. ${ }^{18}$ It is noteworthy that only one item on the CAT and SGRQ asks about sleep and it is not covered by the CCQ. Furthermore, none of these instruments addresses symptoms upon waking in the morning, which patients say are the most troublesome. ${ }^{21}$

The CCQ and CAT were developed for use in routine clinical practice and they have three applications in this setting. First, they can be used to aid dialogue between doctor and patient; the layout of the CAT in particular facilitates this process. Second, the questionnaires may be used for baseline evaluations, to inform treatment decisions, and to guide nonspecialists when to refer a patient 
Table I Instruments used to investigate the effect of COPD on patient health

\begin{tabular}{llll}
\hline Instrument & Use & Advantages & Disadvantages \\
\hline $\mathrm{mMRC}^{16}$ & Dyspnea measurement & Brevity & Lacks sensitivity \\
$\mathrm{SGRQ}^{19}$ & Health status & Covers broad spectrum of COPD effects & Time-consuming \\
$\mathrm{CCQ}^{20}$ & Health status & Brevity & Symptomatic threshold yet to be determined \\
& & Covers broad spectrum of COPD effects & \\
$\mathrm{CAT}^{16,18}$ & Health status & Brevity & Little data about responsiveness to treatment \\
& & Covers broad spectrum of COPD effects & \\
\hline
\end{tabular}

Abbreviations: CAT, COPD Assessment Test; CCQ, Clinical COPD Questionnaire; COPD, chronic obstructive pulmonary disease; mMRC, modified Medical Research Council dyspnea score; SGRQ, St George's Respiratory Questionnaire.

for specialist evaluation. The final, and perhaps the most useful, application is to monitor changes over time by completing the assessment at each visit. Prompt identification of worsening condition permits timely intervention. A worsening score may be due to a number of factors, such as a reduction in adherence to treatment, the development of poor inhaler technique, the occurrence of unreported exacerbations, or rapidly progressive disease that requires further investigation.

\section{Physical activity and COPD Assessing physical activity}

Studies have shown that physical activity declines with advancing COPD, as patients with moderate-to-severe disease had lower activity levels than healthy controls. ${ }^{22-24}$ The most inactive patients were those on oxygen therapy. ${ }^{23}$ Activity levels start to decline early in disease progression; by the time patients reach moderate levels of airflow limitation (GOLD stage II), they are already starting to become inactive. ${ }^{25,26}$ The decline in physical activity in COPD sufferers may correlate with a range of factors, including airflow obstruction, ${ }^{25}$ dynamic hyperinflation, ${ }^{27}$ cardiac dysfunction, ${ }^{28}$ muscle deconditioning and quadriceps strength, ${ }^{29,30}$ and systemic inflammation. ${ }^{28,30}$

There are a number of ways to measure physical activity in patients, including questionnaires, pedometers, and activity monitors with a more advanced technology (accelerometers). ${ }^{31}$ Questionnaires assess the perspective of the patient and are mainly used in epidemiological studies. The main problem of a questionnaire-based assessment of physical activity is that it might be inaccurate on an individual level. This limitation might be overcome by a recently developed, more COPD-specific questionnaire. ${ }^{32}$ Pedometers count the number of steps in a given time period, are widely used in public health campaigns, and have a role as a motivational tool aiming to increase daily activity. Pedometer indices for public health have been defined (Figure 1) ${ }^{33}$ Accelerometers are electronic portable devices that are worn on the body to detect acceleration and thereby reflect body movements. Several accelerometers have been studied for the accuracy of physical activity assessment in COPD. ${ }^{31}$

\section{Impact of physical activity on prognosis}

The systemic consequences of COPD, such as muscle weakness and osteoporosis, commonly arise in inactive patients..$^{34,35}$ Additionally, data suggest that patients with COPD who have low levels of physical activity are more likely to be admitted to hospital. ${ }^{10}$

Preserved levels of physical activity are related to a better prognosis in COPD. In two separate studies, patients with COPD who had different activity levels were followed for 3 years and 5-8 years. The probability of survival was significantly improved in those patients who were more active, even after correcting for lung function and exercise capacity. ${ }^{89}$ One of the studies concluded that the objective measurement of physical activity is the strongest predictor of all-cause mortality in patients. ${ }^{8}$

\section{Improving physical activity: an integrated approach}

An appropriate level of physical activity is very important in patients with COPD, as it plays a key role in maintaining

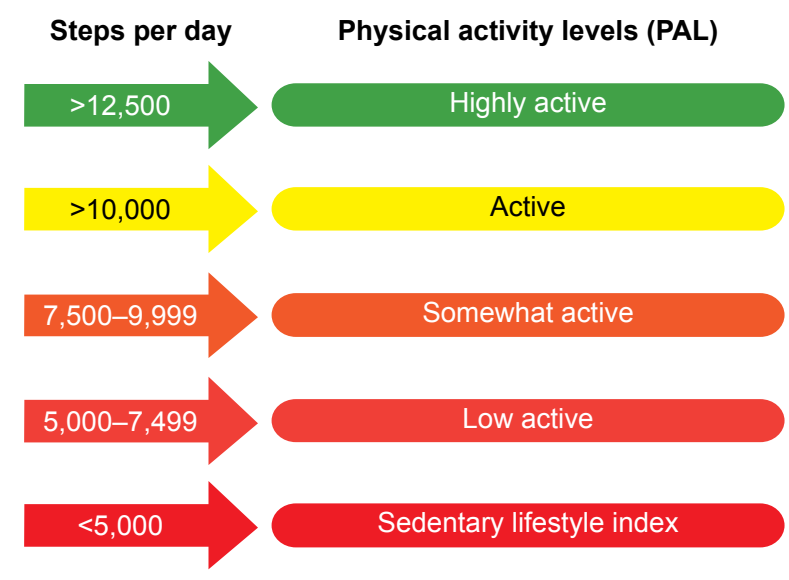

Figure I Pedometer indices for public health. Note: Data from Tudor-Locke et al. ${ }^{33}$ 


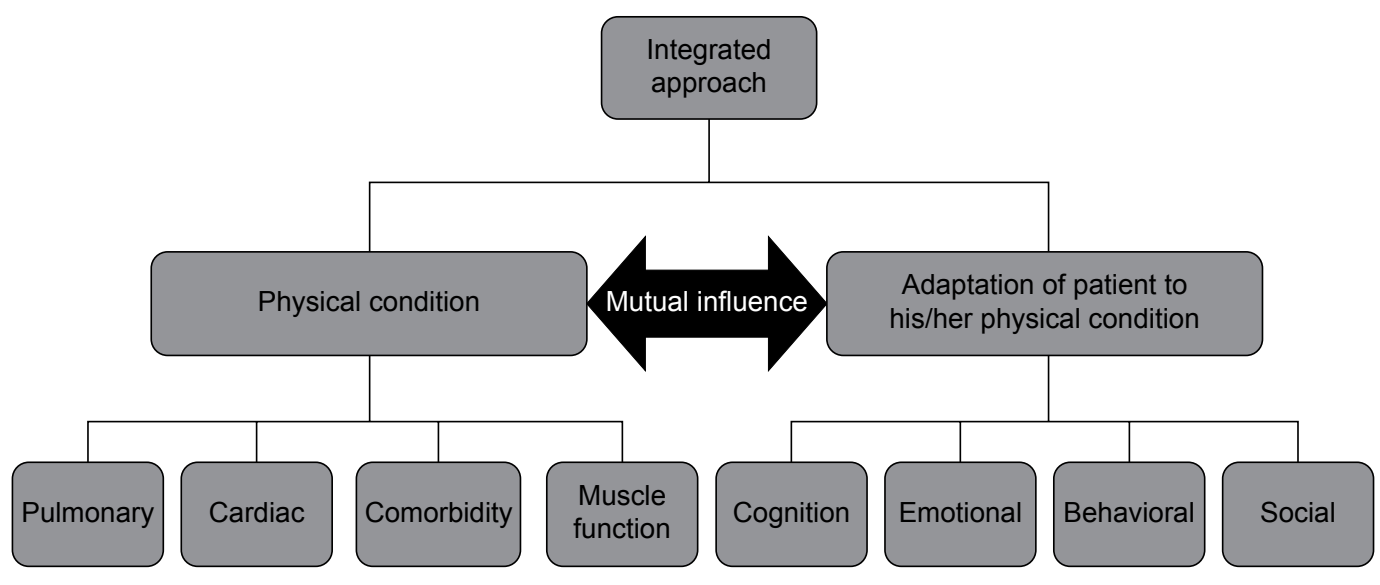

Figure 2 Mapping COPD characteristics.

Abbreviation: COPD, chronic obstructive pulmonary disease.

health. ${ }^{31}$ As in appropriately dosing medication, it is important that the level and timing of physical activity is guided by an overall rehabilitation strategy for the patient. Pulmonary rehabilitation therefore aims to improve the physical and psychological health of patients with chronic respiratory disease, and includes a focus on improving physical activity levels. ${ }^{36}$ Pulmonary rehabilitation techniques can include exercise training (under direct supervision or at home), behavior modification, and education of the patient about COPD. A multidisciplinary team is therefore required to deliver this intervention, including physicians and other health care professionals such as exercise physiologists, occupational therapists, nutritionists, and physiotherapists. ${ }^{5}$ In a study of pulmonary rehabilitation in the form of Nordic walking, movement intensity in daily life significantly improved after 3 months compared with the control group. ${ }^{37}$ Furthermore, in the Nordic walking group, overall time spent sitting per day decreased, while time spent walking and standing per day increased. ${ }^{37}$ Pulmonary rehabilitation has also been shown to reduce symptoms such as dyspnea, improve exercise capacity, and improve QoL. ${ }^{5}$ However, some patients may not be suitable for pulmonary rehabilitation due to underlying health conditions. ${ }^{38}$ It is suggested that continuous motivation and counseling are required to maximize the benefit of this intervention.

The Center for Integrated Rehabilitation Organ Failure $(\mathrm{CIRO}+)$ approach to COPD management utilizes information captured during each individual clinical assessment to create a large and comprehensive data set. The data collected maps COPD characteristics in such a way that each physical condition is linked to the patient's adaptation to the condition. These data have been used as the basis for a framework to assess patients with COPD who have been referred for pulmonary rehabilitation, and a panel of multidisciplinary experts in COPD management devised the framework as shown in Figure 2. In order to treat patients more effectively, the integrated assessment used in CIRO+ categorizes each patient in relation to impairments or risks across several domains: symptoms, functional performance, respiratory impairment, comorbidities, and adaptation. This has now been approved by the Dutch Healthcare Authority (Nederlandse Zorgautoriteit) and is the recommended model for assessing the burden of COPD in the Netherlands.

\section{Challenges of treating complex disease}

\section{Comorbidities}

Chronic diseases such as cardiovascular disease, COPD, and diabetes are complex and multifactorial and frequently present as comorbid conditions. For example, Italian population studies have identified far higher incidence of cardiovascular disease, diabetes, depressive disorders, and osteoporosis among patients with COPD than in the general population. . $^{39,40}$ Comorbidities have a substantial impact on COPD symptoms, patient well-being, and physical activity. ${ }^{38}$ It has been suggested that persistent low-grade systemic inflammation may be the reason why patients with COPD are so frequently affected by comorbidities. ${ }^{41}$ Comorbidities contribute to mortality rates, disease severity, increase the risk of hospitalization, and are of utmost importance given that most elderly patients have two or more chronic morbidities. ${ }^{42}$

Approximately half of all patients with COPD attending $\mathrm{CIRO}+$ have at least four comorbidities, many of which may not be classically associated with COPD, including hypertension (48\%) and hyperglycemia (54\%). Five comorbidity clusters have been identified: metabolic, cardiovascular, 
cachectic, less comorbidity, and psychological. The clustering is clinically important because many of the characteristics defined within them are not well correlated with $\mathrm{FEV}_{1} \cdot{ }^{38}$

Comorbidities make COPD management more challenging and increase the use of health care services. ${ }^{41}$ The discovery of these comorbidity clusters will help alert clinicians to particular groups of comorbidities in patients with COPD, and may influence the development of future treatment guidelines for specific comorbidities. This discovery is of potential benefit to both patients with COPD and clinicians. ${ }^{38}$

\section{Unmet need}

There is a need to improve therapies available to patients whose symptoms are not well-controlled by current treatments. ${ }^{43}$ These patients include those with comorbidities, with serious disease, or with long-term disease which has progressed.

In an effort to overcome the complexity of COPD, there is also a need to detect the condition at an earlier stage, before the onset of airway symptoms. ${ }^{43}$ Current treatments, such as bronchodilators, address the debilitating symptoms of the disease, but not underlying disease progression. Furthermore, inhaled corticosteroids are used in stable COPD despite the fact that there is no solid evidence to support this, except during exacerbations. ${ }^{44}$

Alongside a more tailored use of existing treatments, there is a need for new therapeutic options, such as agents acting at alternative biochemical targets with favorable tolerability and safety profiles. ${ }^{43}$ The inflammatory response involved in COPD is a potential target for the development of new treatments, as signal transduction pathways are activated in order to release proteases and oxidants to initiate cellular responses. $^{44}$

\section{Approaches to improve symptom control \\ Long-acting muscarinic antagonist/long- acting $\beta_{2}$-agonist combination therapy}

Inhaled bronchodilators, either short-acting or long-acting, are the mainstay of therapy in COPD. ${ }^{45}$ The rationale for combining long-acting muscarinic antagonists (LAMAs) and long-acting $\beta_{2}$-agonists (LABAs) is derived from the concept of targeting complementary pathways to achieve maximal bronchodilation. Smooth muscle bronchoconstriction is controlled via the parasympathetic nervous system, mediated by acetylcholine, and the sympathetic nervous system can stimulate bronchodilation via the adrenergic system. Simultaneous inhibition of $\mathrm{M}_{2} / \mathrm{M}_{3}$ receptors by muscarinic antagonists and activation of $\beta_{2}$-receptors by $\beta_{2}$-agonists has been shown to achieve additive bronchodilatory effects (Figure 3). ${ }^{46,47}$ Indeed, a recent preclinical study has demonstrated that there may be a complementary interaction between concomitantly administered LAMA and LABA in human airways. ${ }^{48}$

LAMA/LABA combination therapy is especially useful in patients whose COPD symptoms are insufficiently controlled by maintenance monotherapy, ${ }^{47,49}$ such as difficultto-treat patients with comorbidities. ${ }^{38}$

Many patients with COPD find that their symptoms are at their worst in the early morning and at night. Symptoms such as coughing, general fatigue, and tiredness are commonly

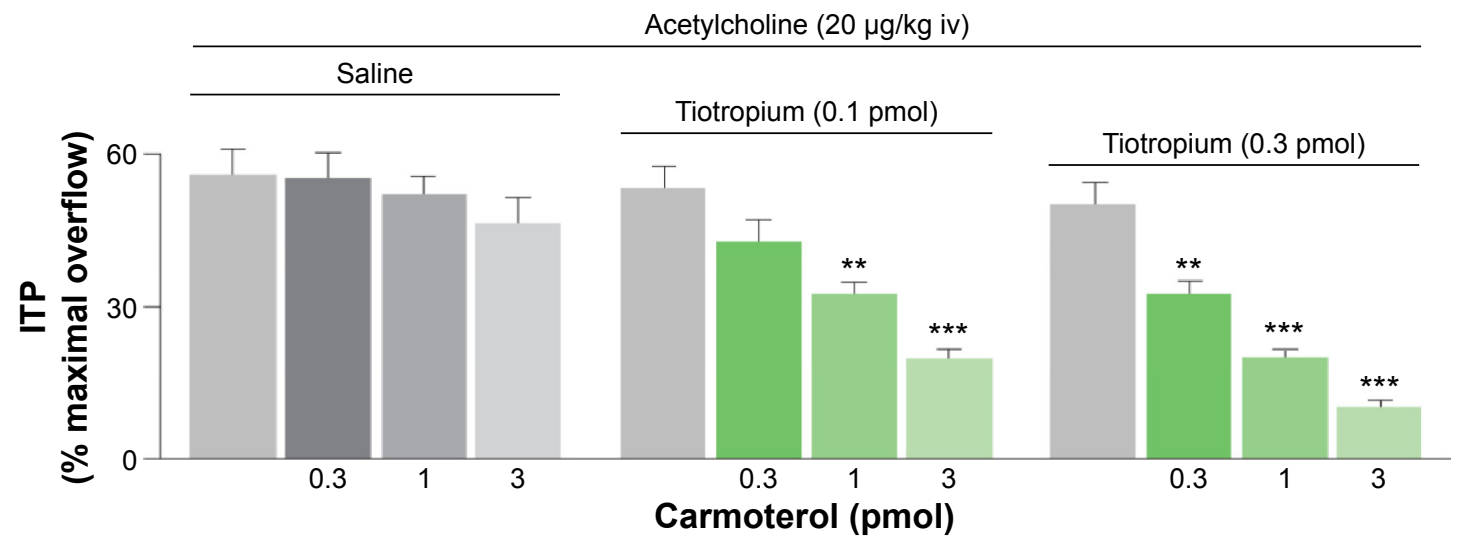

Figure 3 Synergistic bronchodilator effect from the simultaneous blockade of $M_{2} / M_{3}$ receptors and the activation of $\beta_{2}$-adrenoceptors.

Notes: Gray columns indicate the effect of saline or tiotropium on ACh-induced bronchoconstriction in the absence of carmoterol (control) in anesthetized guinea pigs. $* * P<0.01$ and $* * * P<0.001$ versus corresponding control. Values are mean \pm standard error of the mean of six to eight different animals. Adapted from Pulmonary Pharmacology \& Therapeutics, Vol 20, Issue 3, Rossoni G, Manfredi B, Razzetti R, Civelli M, Berti F, Positive interaction of the novel $\beta_{2}$-agonist carmoterol and tiotropium bromide in the control of airway changes induced by different challenges in guinea-pigs. Pages 250-257, Copyright 2007, with permission from Elsevier. ${ }^{47}$ Abbreviations: ACh, acetylcholine; ITP, intratracheal pressure; iv, intravenous. 
experienced in the morning, with $50 \%$ of patients with severe COPD experiencing these immediately upon waking on all or most days. ${ }^{14}$ Furthermore, $37 \%$ of all patients with COPD were woken up by their symptoms on at least 3 days per week. ${ }^{14}$ At night, patients experiencing symptoms such as fatigue, tiredness, and back pain stated their symptoms were worse than normal. ${ }^{14}$ To help alleviate early morning and nighttime symptoms, patients must ensure that they take their medication at the optimum time and physicians must advise patients on the most suitable time to take their medication. $^{14}$

Bronchodilator therapy is known to improve exercise tolerance and exertional dyspnea in patients with COPD, ${ }^{50}$ but may also improve physical activity, as has recently been demonstrated for the LAMA aclidinium and for the LABA indacaterol. ${ }^{51,52}$

\section{Optimizing delivery}

Drug therapy in COPD is reliant on both the efficacy of the inhaled medication and the inhaler device used for its delivery. The issue of effectiveness of inhaler devices is complex; for example, comparative data from observational studies in asthma have alternately reported that dry powder inhalers (DPIs) and pressurized metered-dose inhalers (pMDIs) result in better disease control compared with each other. ${ }^{53,54}$ These conflicting results highlight the need for real-world evidence on device effectiveness, as inhaler device selection may affect clinical outcomes. ${ }^{54}$

Three key components intrinsic to an inhaler device determine a device's efficacy: airflow resistance, the mass of the drug particle delivered, and inspiratory flow.

The first of these components, airflow resistance, varies widely between devices. A medium-resistance device is optimal as some patients with COPD may have difficulty generating enough inspiratory effort to use a high-resistance device. $^{55}$

An inhaler must be able to deliver the required mass of drug particle to the correct locations in order to achieve optimal results. Different-sized particles are distributed in the lung according to the size of the airway region; larger particles remain in central, larger areas, whereas smaller particles are deposited in the smaller distal airway. Inhaler devices generate particles of different sizes, which are deposited to different regions of the respiratory tract. ${ }^{56}$ Both DPIs and pMDIs have a large pharyngeal disposition. An adjunct to the pMDI, the valved holding chamber, can be used to improve drug deposition to the lungs by reducing the overall particle size of the aerosol by filtering out larger particles and also reducing the speed of the particles, which results in lesser upper airway deposition. ${ }^{57}$

The inspiratory flow rate, which is the speed of inhalation, varies widely between devices and is known to influence drug delivery and consequently, $\mathrm{FEV}_{1}{ }^{56,58}$ Study results have demonstrated that faster inspiratory flows lead to decreased particle deposition in the lungs. ${ }^{56}$

Correct inhaler technique is another factor which is crucial for drug delivery to the lungs. Despite patients receiving detailed instructions, there is still potential for user error. Critical errors that occur with inhaler use include poor coordination of the device, breathing in too fast and failing to hold the breath. ${ }^{59}$ The incidence of these critical errors increases with age and disease severity. ${ }^{60}$ Incorrect inhaler technique has been shown to be related to increases in hospitalization, emergency visits, and medical interventions. In 1,664 patients with COPD and asthma using DPI and pMDI inhalers at home, critical errors were seen with all of the inhalers studied. ${ }^{61}$

Different devices are associated with varying critical error rates. ${ }^{59,61}$ Easy-to-use devices may help to reduce error rates; however, regardless of the device, it is important to offer correct training and check patients' technique on a regular basis to ensure optimal delivery of product and hence, achieve optimal symptom control. ${ }^{62}$

\section{Conclusion}

COPD symptoms have a detrimental impact on the daily lives of patients, and this can be assessed using short health-status questionnaires. Nighttime and early morning symptoms can be very disruptive to patients and should be enquired about specifically during consultations.

Physical inactivity is a key feature and direct consequence of the symptoms of COPD. Instigating approaches to increase physical activity can potentially improve prognosis. One such approach, pulmonary rehabilitation with multidisciplinary support, can potentially improve physical inactivity, which will impact on general health.

Considerations should also be made for optimizing the use of therapeutic interventions available to meet patients' needs, including appropriate selection of inhaled medication (according to efficacy) and the inhaler device used for its delivery, and introduction of LAMA/LABA combination therapy. Use of the correct inhaler technique by the patient must be ensured.

An approach to disease management that focuses on the consequences of COPD symptoms from the patient perspective can help to improve aspects of QoL and subsequent outcomes in patients with COPD. 


\section{Acknowledgments}

Medical writing support was provided by Kimberley Haines on behalf of Complete Medical Communications, funded by Almirall S.A., Barcelona, Spain.

\section{Disclosure}

Professor Jones has previously received speaker fees and has served on advisory boards for Almirall, AstraZeneca, Chiesi, GlaxoSmithKline, Novartis, Roche, and Spiration, and has received research grants from GlaxoSmithKline. All fees were contracted via his institution. Professor Jones is also employed as a Global Medical Expert by GlaxoSmithKline.

Professor Watz has previously received speaker fees from Almirall, AstraZeneca, Berlin Chemie, Boehringer Ingelheim, Chiesi, GlaxoSmithKline, Janssen, and Novartis.

Professor Wouters has previously received honoraria for speaking and consulting from Almirall, AstraZeneca, Boehringer Ingelheim, Chiesi, Danone, GlaxoSmithKline, and Pfizer, and has received research grants from AstraZeneca, Boehringer Ingelheim, Danone, and GlaxoSmithKline.

Professor Cazzola has previously received honoraria for speaking and consulting and/or financial support for attending meetings from Abbott, Almirall, AstraZeneca, Boehringer Ingelheim, Chiesi, Dey, GlaxoSmithKline, Guidotti, Lallemand, Malesci, Menarini, Mundipharma, Novartis, Pfizer, Sanovel, Sigma Tau, Takeda, and Valeas.

\section{References}

1. Decramer M, Janssens W, Miravitlles M. Chronic obstructive pulmonary disease. Lancet. 2012;379(9823):1341-1351.

2. Blasi F, Cesana G, Conti S, et al. The clinical and economic impact of exacerbations of chronic obstructive pulmonary disease: a cohort of hospitalized patients. PLoS One. 2014;9(6):e101228.

3. Roggeri A, Micheletto C, Roggeri DP. Outcomes and costs of treating chronic obstructive pulmonary disease with inhaled fixed combinations: the Italian perspective of the PATHOS study. Int $J$ Chron Obstruct Pulmon Dis. 2014;9:569-576.

4. Rennard S, Decramer M, Calverley PM, et al. Impact of COPD in North America and Europe in 2000: subjects' perspective of Confronting COPD International Survey. Eur Respir J. 2002;20(4): 799-805.

5. Spruit MA, Singh SJ, Garvey C, et al. An official American Thoracic Society/European Respiratory Society statement: key concepts and advances in pulmonary rehabilitation. Am J Respir Crit Care Med. 2013;188(8):e13-e64.

6. Miravitlles M, Worth $\mathrm{H}$, Soler Cataluña J, et al. Observational study to characterise 24-hour COPD symptoms and their relationship with patient-reported outcomes: results from the ASSESS study. Respir Res. 2014;15(1):122.

7. Riario-Sforza GG, Yacoub MR, Incorvaia C. Pulmonary rehabilitation as evaluated by clinical trials: an overview. Rev Recent Clin Trials. 2010;5(2):76-84.

8. Waschki B, Kirsten A, Holz O, et al. Physical activity is the strongest predictor of all-cause mortality in patients with COPD: a prospective cohort study. Chest. 2011;140(2):331-342.
9. Garcia-Rio F, Rojo B, Casitas R, et al. Prognostic value of the objective measurement of daily physical activity in patients with COPD. Chest. 2012;142(2):338-346.

10. Garcia-Aymerich J, Lange P, Benet M, Schnohr P, Anto JM. Regular physical activity reduces hospital admission and mortality in chronic obstructive pulmonary disease: a population based cohort study. Thorax. 2006;61(9):772-778.

11. Global Initiative for Chronic Obstructive Lung Disease (GOLD). Global strategy for the diagnosis, management, and prevention of chronic obstructive pulmonary disease. Available at: http://www.goldcopd. org/uploads/users/files/GOLD_Report_2015_Feb18.pdf. Accessed December 9, 2015

12. Simon KM, Carpes MF, Correa KS, dos Santos K, Karloh M, Mayer AF. Relationship between daily living activities (ADL) limitation and the BODE index in patients with chronic obstructive pulmonary disease. Rev Bras Fisioter. 2011;15(3):212-218.

13. Price D, Small M, Milligan G, Higgins V, Garcia Gil E, Estruch J. Impact of night-time symptoms in COPD: a real-world study in five European countries. Int J Chron Obstruct Pulmon Dis. 2013;8:595-603.

14. Partridge MR, Karlsson N, Small IR. Patient insight into the impact of chronic obstructive pulmonary disease in the morning: an internet survey. Curr Med Res Opin. 2009;25(8):2043-2048.

15. Tsiligianni I, Kocks J, Tzanakis N, Siafakas N, van der Molen T. Factors that influence disease-specific quality of life or health status in patients with COPD: a review and meta-analysis of Pearson correlations. Prim Care Respir J. 2011;20(3):257-268.

16. Han MK, Muellerova H, Curren-Everett D, et al. GOLD 2011 disease severity classification in COPDGene: a prospective cohort study. Lancet. 2012;1(1):43-50.

17. Mullerova H, Lu C, Li H, Tabberer M. Prevalence and burden of breathlessness in patients with chronic obstructive pulmonary disease managed in primary care. PLoS One. 2014;9(1):e85540.

18. Jones PW, Harding G, Berry P, Wiklund I, Chen WH, Kline Leidy N. Development and first validation of the COPD Assessment Test. Eur Respir J. 2009;34(3):648-654.

19. Jones PW, Quirk FH, Baveystock CM. The St George's Respiratory Questionnaire. Respir Med. 1991;85 Suppl B:25-31.

20. van der Molen T, Willemse BW, Schokker S, Ten Hacken NH, Postma DS, Juniper EF. Development, validity and responsiveness of the clinical COPD Questionnaire. Health Qual Life Outcomes. 2003;1:13.

21. Kessler R, Partridge MR, Miravitlles M, et al. Symptom variability in patients with severe COPD: a pan-European cross-sectional study. Eur Respir J. 2011;37(2):264-272.

22. Singh S, Morgan MD. Activity monitors can detect brisk walking in patients with chronic obstructive pulmonary disease. $J$ Cardiopulm Rehabil. 2001;21(3):143-148.

23. Sandland CJ, Singh SJ, Curcio A, Jones PM, Morgan MD. A profile of daily activity in chronic obstructive pulmonary disease. $J$ Cardiopulm Rehabil. 2005;25(3):181-183.

24. Schonhofer B, Ardes P, Geibel M, Kohler D, Jones PW. Evaluation of a movement detector to measure daily activity in patients with chronic lung disease. Eur Respir J. 1997;10(12):2814-2819.

25. Watz H, Waschki B, Meyer T, Magnussen H. Physical activity in patients with COPD. Eur Respir J. 2009;33(2):262-272.

26. Troosters T, Sciurba F, Battaglia S, et al. Physical inactivity in patients with COPD, a controlled multi-center pilot-study. Respir Med. 2010;104(7):1005-1011.

27. Garcia-Rio F, Lores V, Mediano O, et al. Daily physical activity in patients with chronic obstructive pulmonary disease is mainly associated with dynamic hyperinflation. Am J Respir Crit Care Med. 2009;180(6): 506-512.

28. Watz H, Waschki B, Boehme C, Claussen M, Meyer T, Magnussen H. Extrapulmonary effects of chronic obstructive pulmonary disease on physical activity: a cross-sectional study. Am J Respir Crit Care Med. 2008;177(7):743-751.

29. Shrikrishna D, Patel M, Tanner RJ, et al. Quadriceps wasting and physical inactivity in patients with COPD. Eur Respir J. 2012;40(5):1115-1122. 
30. Waschki B, Spruit MA, Watz H, et al. Physical activity monitoring in COPD: compliance and associations with clinical characteristics in a multicenter study. Respir Med. 2012;106(4):522-530.

31. Watz H, Pitta F, Rochester CL, et al. An official European Respiratory Society statement on physical activity in COPD. Eur Respir J. 2014; 44(6):1521-1537.

32. Gimeno-Santos E, Raste Y, Demeyer H, et al. The PROactive instruments to measure physical activity in patients with chronic obstructive pulmonary disease. Eur Respir J. 2015;46:988-1000.

33. Tudor-Locke C, Williams JE, Reis JP, Pluto D. Utility of pedometers for assessing physical activity: construct validity. Sports Med. 2004; 34(5):281-291.

34. Decramer M, Janssens W. Chronic obstructive pulmonary disease and comorbidities. Lancet Respir Med. 2013;1(1):73-83.

35. Waschki B, Kirsten AM, Holz O, et al. Disease progression and changes in physical activity in patients with chronic obstructive pulmonary disease. Am J Respir Crit Care Med. 2015;192(3):295-306.

36. Spruit MA, Pitta F, McAuley E, ZuWallack RL, Nici L. Pulmonary rehabilitation and physical activity in patients with COPD. Am J Respir Crit Care Med. 2015;192:924-933.

37. Breyer MK, Breyer-Kohansal R, Funk GC, et al. Nordic walking improves daily physical activities in COPD: a randomised controlled trial. Respir Res. 2010;11:112.

38. Vanfleteren LE, Spruit MA, Groenen M, et al. Clusters of comorbidities based on validated objective measurements and systemic inflammation in patients with chronic obstructive pulmonary disease. Am J Respir Crit Care Med. 2013;187(7):728-735.

39. Cazzola M, Bettoncelli G, Sessa E, Cricelli C, Biscione G. Prevalence of comorbidities in patients with chronic obstructive pulmonary disease. Respiration. 2010;80(2):112-119.

40. Cazzola M, Calzetta L, Bettoncelli G, et al. Cardiovascular disease in asthma and COPD: a population-based retrospective cross-sectional study. Respir Med. 2012;106(2):249-256.

41. Barnes PJ, Celli BR. Systemic manifestations and comorbidities of COPD. Eur Respir J. 2009;33(5):1165-1185.

42. Barnett K, Mercer SW, Norbury M, Watt G, Wyke S, Guthrie B. Epidemiology of multimorbidity and implications for health care, research, and medical education: a cross-sectional study. Lancet. 2012;380(9836): 37-43.

43. Bousquet J, Anto JM, Sterk PJ, et al. Systems medicine and integrated care to combat chronic noncommunicable diseases. Genome Med. 2011; 3(7):43.

44. Hele DJ, Belvisi MG. Novel therapies for the treatment of inflammatory airway disease. Expert Opin Investig Drugs. 2003;12(1):5-18.

45. Cazzola M, Bardaro F, Stirpe E. The role of indacaterol for chronic obstructive pulmonary disease (COPD). J Thorac Dis. 2013;5(4): 559-566.

46. Cazzola M, Page CP, Calzetta L, Matera MG. Pharmacology and therapeutics of bronchodilators. Pharmacol Rev. 2012;64(3):450-504.
47. Rossoni G, Manfredi B, Razzetti R, Civelli M, Berti F. Positive interaction of the novel beta(2)-agonist carmoterol and tiotropium bromide in the control of airway changes induced by different challenges in guinea-pigs. Pulm Pharmacol Ther. 2007;20(3):250-257.

48. Cazzola M, Calzetta L, Page CP, et al. Pharmacological characterization of the interaction between aclidinium bromide and formoterol fumarate on human isolated bronchi. Eur J Pharmacol. 2014;745:135-143.

49. Matera MG, Page CP, Cazzola M. Novel bronchodilators for the treatment of chronic obstructive pulmonary disease. Trends Pharmacol Sci. 2011;32(8):495-506.

50. Maltais F, Celli B, Casaburi R, et al. Aclidinium bromide improves exercise endurance and lung hyperinflation in patients with moderate to severe COPD. Respir Med. 2011;105(4):580-587.

51. Beeh KM, Watz H, Puente-Maestu L, et al. Aclidinium improves exercise endurance, dyspnea, lung hyperinflation, and physical activity in patients with COPD: a randomized, placebo-controlled, crossover trial. BMC Pulm Med. 2014;14(1):209.

52. Watz H, Krippner F, Kirsten A, Magnussen H, Vogelmeier C. Indacaterol improves lung hyperinflation and physical activity in patients with moderate chronic obstructive pulmonary disease - a randomized, multicenter, double-blind, placebo-controlled study. BMC Pulm Med. 2014; $14: 158$.

53. Price D, Roche N, Christian VJ, et al. Device type and real-world effectiveness of asthma combination therapy: an observational study. Respir Med. 2011;105(10):1457-1466.

54. Price D, Haughney J, Sims E, et al. Effectiveness of inhaler types for real-world asthma management: retrospective observational study using the GPRD. J Asthma Allergy. 2011;4:37-47.

55. Magnussen H, Watz H, Zimmermann I, et al. Peak inspiratory flow through the Genuair ${ }^{\mathbb{R}}$ inhaler in patients with moderate or severe COPD. Respir Med. 2009;103(12):1832-1837.

56. Usmani OS, Biddiscombe MF, Barnes PJ. Regional lung deposition and bronchodilator response as a function of beta2-agonist particle size. Am J Respir Crit Care Med. 2005;172(12):1497-1504.

57. Dolovich MB, Macintyre NR, Anderson PJ, et al. Consensus statement: aerosols and delivery devices. J Aerosol Med. 2000;13(3):291-300.

58. Hill LS, Slater AL. A comparison of the performance of two modern multidose dry powder asthma inhalers. Respir Med. 1998;92(1):105-110.

59. Sanchis J, Corrigan C, Levy ML, Viejo JL. Inhaler devices - from theory to practice. Respir Med. 2013;107(4):495-502.

60. Wieshammer S, Dreyhaupt J. Dry powder inhalers: which factors determine the frequency of handling errors? Respiration. 2008;75(1): $18-25$.

61. Melani AS, Bonavia M, Cilenti V, et al. Inhaler mishandling remains common in real life and is associated with reduced disease control. Respir Med. 2011;105(6):930-938.

62. Khassawneh BY, Al-Ali MK, Alzoubi KH, et al. Handling of inhaler devices in actual pulmonary practice: metered-dose inhaler versus dry powder inhalers. Respir Care. 2008;53(3):324-328.
International Journal of COPD

\section{Publish your work in this journal}

The International Journal of COPD is an international, peer-reviewed journal of therapeutics and pharmacology focusing on concise rapid reporting of clinical studies and reviews in COPD. Special focus is given to the pathophysiological processes underlying the disease, intervention programs, patient focused education, and self management protocols.

\section{Dovepress}

This journal is indexed on PubMed Central, MedLine and CAS. The manuscript management system is completely online and includes a very quick and fair peer-review system, which is all easy to use. Visit http://www.dovepress.com/testimonials.php to read real quotes from published authors. 